\title{
Investigating the Quality Performance of Production of Some Selected Drinks using Hotelling T-Square Control Chart
}

\author{
Akomolafe A. A. \\ Department of Statistics, Federal University of Technology, Akure, Ondo state, Nigeria
}

\begin{abstract}
Consumers make complaint about the state of home-made goods. Some of the consumers claim that foreign goods are of high quality compared to home-made goods. We discovered that many indigenous industries are no more in existence and so this brought the desire to carry out this research work so as to find out whether products from our indigenous brewery industry fall within the acceptance region and devoid of the consumers' complaint. For clarity and easy handling of this topic, data were collected on the four major components that are produced [STAR, MALTINA AND GOLDBERG] for months. The data collected covered a period of four months and the readings were twice a day. This was culled from the company's register and averaged. Control charts, Standard Deviation charts and Cumulative Sum Technique charts (CUSUM) and Hotellings T-square were used in the analysis. The results were presented with the use of chart and tables. The results indicated the three beer product considered fall within the acceptance region considering their fill height and the level of carbon iv oxide [ $\left.\mathrm{CO}_{2}\right]$.
\end{abstract}

Keywords: Control charts, Cumulative Sum Technique charts, Hotellings T-square, fill height, level of carbon iv oxide $\left[\mathrm{CO}_{2}\right]$.

DOI: $10.7176 / \mathrm{IEL} / 12-1-02$

Publication date: January $31^{\text {st }} 2022$

\section{INTRODUCTION}

It has been in the mind of people from the onset of creation of industries that goods to be produced by these industries be of good quality. This is the reason why the Federal Government of Nigeria came up with legislations to protect the buyers from buying inferior goods. The urge to have high quality goods is the desire of every nation. As breweries have increased in size, and as consumer buys given type of beer his brain national brand marketing of beer has been contains "brand-image, the need for quality control has expectation derived from advertising, previous grown. Quality control relies partly upon drinking etc. When he receives the beer the measurement of attributes such as fill height and level of $\mathrm{co}_{2}$. A fact stands, that good products and services sell themselves. This accounts for the reason why in manufacturing, quality control is involved in developing systems to ensure standard products or services are designed, and produced to meet or exceed customer's requirements. All things being equal, we will always want to go for and enjoy quality products or services because we think in terms of its excellence in fulfilling our expectations. These expectations are based on "fitness for use" and selling price of the product. For instance, an individual who purchase a refrigerator expects it to be defect free and to provide years of reliability and high performance service. If the refrigerator performs as desired, it is fit for use but if otherwise, then it is not fit for use.

Changes in the production process may be due to one or more of these four major causes.

- Man: probably the largest source of deviations is man. The workers may be careless, incompetent or even mentally unstable at the time of production. They may lack commitment or even passion for work.

- Material: raw materials used in manufacturing are mostly products of another manufacturing process. Since we have known that every product has deviations, it follows that we also have to expect deviations in the raw materials. The raw materials may not be of the right type, it may also be of poor quality.

- Machines: this may lead to deviations as a result of play of bearings, vibrations, wear and tear in machine parts and tools, instability in the supply of electricity, water and air, oil or stream pressure. The machine may require reset, or to be repaired, or adjusted etc.

- Method: the method of production of a product is also a source of deviation in the product. The method is interplay of man, machines, inflow as well as outflow of materials which are themselves sources of deviations.

Walter Shewhart introduced the concept of statistical quality control- controlling quality of mass produced goods. Shewhart believed that variation always exists in manufactured products and that the variation can be studied, monitored and controlled using Statistics. It was W. Edwards Deming born in 1900 that was credited for turning the situation of shattered economies of Europe and Japan through his works. He was introduced to Walter Shewhart who explained the theories about using statistical control charts to improve quality and productivity in which case he developed 14 points agenda in which if followed would enable a company to improve quality and 
productivity, reduce costs and compete effectively in the world market.

\section{LITERATURE REVIEW}

Reeves and Bednar (1994) define quality as excellence, value, conformance to specifications, and meeting or exceeding customers' expectation. The term "fitness for use" defined by Juran (1974) is also included in the quality definition presented by Reeves and Bednar (1994). Thus, the customer perspective with respect to quality is the master key that should be understood while determining any term for quality or definition of quality. Hanna, S.J. and McLaughlin, J.F. (1966) worked on the Application of Statistical Quality Control Techniques to Pint and HalfGallon Ice cream packaging operation, using Statistical Quality Control, and they were able to detect error by simply inspecting the process. A suitable corrective measure was taken to ensure uniformity of the products. Deming, W.E (1986). worked on Quality and Productivity Improvement using acceptance sampling method, and he was able to obtain increase in quality and simultaneous reduction in the of cost by reducing waste, re write staff attrition and litigation while increasing customer's loyalty.

Farhat, B.A. and Al- Darrab, I.(1998). Total quality management is now established and widely used management process. One of its associated features is the application of statistical quality control techniques. A quality product or service is one that meets the customer's needs and provides the value that they want and expect. They are also of the opinion that quality management is a formal approach to management in which the overriding priority of the organization is to deliver a quality product or service and to work towards excellence and continuous improvement in everything it does.

Quality can be viewed from the perspectives of design and product in which case; design quality is the different grades or levels of performance, reliability, serviceability and function that are the results of deliberate engineering and management decision. On the other hand, product quality is the conformance of the product with specifications or expectations of the user in terms of fitness for use and cost. They are also of the opinion that control charts are closely related with statistical test of hypothesis. The control chart is a test of hypothesis that the process is in a state of statistical control. Every point plotted within the control limits fall within the acceptance region and leads to acceptance of the null hypothesis while any point plotted outside the control limits leads to the rejection of the null hypothesis that the system is under control.

Shrestha and Chalidabhongse (2006) explained over their survey on 300 employees working in 60 Thai companies to what extent job satisfaction is affected by the existing performance appraisal system used by these companies. They conclude that since the performance appraisal system is part of the company's running processes, employees would show lower performance level if the appraisal system is not satisfactorily controlled. Their results were then further used in quantifying the performance measurement system aimed at ensuring employee satisfaction. Jiang et al. (2007) addressed the impact of job dissatisfaction on the global supply chain. Their research was a survey based on coastal industries in China, and the results from the study were used in assisting the managers in understanding the implications and successfully dealing with labor related risks.

Cooper (2008) have emphasized on the impact of TQM practices on job satisfactions. The main aim of their research was to examine the relationship between people-related TQM practices and job satisfaction of service employees. The study triggers the question whether a TQM has an effect on employees' satisfaction. Pitterman (2000)'s findings on Telecordia technologies showed that customer satisfaction figures had gone up from $60 \%$ in 1992 to $95 \%$ at the time of implementing ISO 9001 quality system. Also, there was a $63 \%$ reduction noted in test cost efficiency since 1993 that $98 \%$ of major software released by Telcordia between 1995 and 1998 were delivered in time, even though the number of releases had tripled during the four year time.

Takala et al. (2006) have gone even further to seeking customer satisfaction by improving and ensuring that customer satisfaction survey is supposed to be well designed and validated in order to be an effective measurement tool for its intended purpose. In their research paper, the purpose was to verify the reliability of customer satisfaction survey in context to three aspects of service; quality, delivery and responsiveness. Takala et al. (2006) concluded that there was a need to work on the flexibility of the customer satisfaction survey to ensure the reliability in the qualitative analysis of the supply chain.

Tang and Wang (2008) have also done the same by improving the fulfilment of the customer satisfaction requirement in (International Organization for Standardization, ISO 9001:2008(E)). They suggested a method to help companies manage the questionnaires delivered to their customers that was via contracting such a service to a third party organization, the so called application service provider (ASP). Their results suggested that real-time data analysis can help organizations in meeting the needs of the customers and providing the best quality service at low cost and with high efficiency. Abdur, R. and Hiroshi, O. (2004). They both worked on an Integrated Optimization model for inventory and Quality control problem, using Statistical quality control and they were able to reach a conclusion as to whether the process is in control or not and also the optimal decision variables of the economic model.

Sitko-Lutek et al. (2010) examined the customer complaint handling process with respect to the information quality, thereby suggesting possible areas of improvements in the process. Their research method involved in 
reviewing documents, complaint handling procedures and interviews through a social network analysis (SNA) model. The software used for SNA was UCInet. The results suggested that process engineering leadership played a vital and responsive role in disseminating quality assurance information to other staff, and it also suggested that an identification in potential areas of process improvements, will thereby enhance, and improve customer satisfaction. Another was of achieving customer satisfaction, in a work organization, is to enhance the internal quality audit process for the existing quality management systems.

\section{METHODOLOGY}

A control chart is a graphical representation that shows whether a sample data falls within a normal range of variation. It used to know if a process is in statistical quality control or not. It is also a graphical representation of mathematical model used to monitor a process in order to detect changes in parameter of that process. It displays the quality characteristics that has been measured or computed from a sample against the sample number or time. They are simple to construct and to interpret as they employ a center line (denoted as CNL) and two major control limits; an upper control limit (denoted as UCL) and a lower control limit (denoted as LCL). The center line represents the average performance of the process when it is in a state of statistical control- that is, when only common cause variation exists. The upper and lower control limits are horizontal lines situated above and below the center line. These control limits are established so that when the process is in control, almost all plots will be between the upper and lower limits.

In practice,

- If all observed plot points are between the LCL and UCL and if no unusual pattern of points exists, we have no evidence that assignable causes exist and we assume that the process is in statistical control. In this case, only common causes of the process variation exist, and no action to remove assignable causes is taken on the process. If we were to take such action, we would be unnecessarily tempering with the process.

- If we observe one or more plot points outside the control limits, then we have evidence that the process is out of control due to one or more assignable causes. Here we must take action on the process to remove those assignable causes.

\section{MULTIVARIATE QUALITY CONTROL CHART}

Multivariate methods that consider the variables jointly are required. Process-monitoring problems in which several related variables are of interest are sometimes called multivariate quality-control (or process-monitoring) problems. The original work in multivariate quality control was done by Hotelling (1947), who applied his procedures to bombsight data during World War II. Subsequent research dealing with control procedures for several related variables include Hicks (1955), Jackson (1956, 1959, 1985), Crosier (1988), Hawkins (1991, 1993b), Lowry et al. (1992), Lowry and Montgomery (1995), Pignatiello and Runger (1990), Tracy, Young, and Mason (1992), Montgomery and Wadsworth (1972), and Alt (1985). This subject is particularly important today, as automatic inspection procedures make it relatively easy to measure many parameters on each unit of product manufactured.

The Hotelling $T^{2}$ chart is the analog of the Shewhart $x$ chart. Multivariate control charts work well when the number of process variables is not too large - say, 10 or fewer. As the number of variables grows, however, traditional multivariate control charts lose efficiency with regard to shift detection. A multivariate approach should be used to monitor process stability with more than one important characteristic. This approach can account for correlations between characteristics and will control the overall probability of falsely signaling a special cause of variation when one is not present. The most common multivariate chart is the $\mathrm{T}^{2}$ chart. There are many situations in which the simultaneous monitoring or control of two or more related quality characteristics is necessary. For example, suppose that a product (paint) is made from two major raw materials, say Titherni (used only in the production of white paint) $\left(x_{1}\right)$ and water $\left(x_{2}\right)$ that together produce white paint. Suppose that $x_{1}$ and $x_{2}$ have independent normal distributions. Because both quality characteristics are measurements, they could be monitored by applying the usual $x$ chart to each characteristic. The process is considered to be in control only if the sample means $\mathrm{x}_{1}$ and $\mathrm{x}_{2}$ and fall within their respective control limits. Monitoring these two quality characteristics independently can be very misleading. So it is best we use the Hotelling $T^{2}$ control chart.

The Multivariate Normal Distribution

In univariate statistical quality control, we generally use the normal distribution to describe the behaviour of a continuous quality characteristic. The univariate normal probability density function is

$$
f(x)=\frac{1}{\sqrt{2 \pi \sigma^{2}}} e^{-\frac{1}{2}\left(\frac{x-\mu}{\sigma}\right)^{2}} \quad-\infty<x<\infty \ldots
$$

The mean of the normal distribution is $\boldsymbol{\mu}$ and the variance is $\boldsymbol{\sigma}^{2}$. Note that (apart from the minus sign) the term in the exponent of the normal distribution can be written as follows:

$$
(x-\mu)\left(\sigma^{2}\right)^{-1}(x-\mu)
$$


This quantity measures the squared standardized distance from $x$ to the mean, where by the term "standardized" we mean that the distance is expressed in standard deviation units. This same approach can be used in the multivariate normal distribution case. Suppose that we have $p$ variables, given by $x_{1}, x_{2}, \ldots, x_{p}$. Arrange these variables in a $p$-component vector $\mathrm{x}^{\prime}=\left[x_{1}, x_{2}, \ldots, x_{p}\right]$. Let $\boldsymbol{\mu}^{1}=\left[\boldsymbol{\mu}, \boldsymbol{\mu}_{2}, \ldots, \boldsymbol{\mu}_{p}\right]$ be the vector of the means of the $x$ 's, and let the variances and covariances of the random variables in $\mathrm{x}$ be contained in a $p * p$ covariance matrix $\Sigma$. The main diagonal elements of $\Sigma$ are the variances of the $x$ 's and the off-diagonal elements are the covariances. Now the squared standardized (generalized) distance from $\mathrm{x}$ to $\boldsymbol{\mu}$ is

$$
(\boldsymbol{x}-\boldsymbol{\mu})^{\prime} \boldsymbol{\Sigma}^{-1}(\boldsymbol{x}-\boldsymbol{\mu})
$$

The multivariate normal density function is obtained simply by replacing the standardized distance in equation $(.2)$ by the multivariate generalized distance in equation (3) and changing the constant term to a more general form that makes the area under the probability density function unity regardless of the value of $p$. Therefore, the multivariate normal probability density function is

$$
f(x)=\frac{1}{(2 \pi)^{p / 2}|\Sigma|^{1 / 2}} e^{-\frac{1}{2}(x-\mu)^{\prime} \Sigma^{-1}(x-\mu)}
$$

where $\quad-\infty<\boldsymbol{x}_{\boldsymbol{j}}<\infty, \quad j=1,2, \ldots, p$.

A multivariate normal distribution for $p=2$ variables (called a bivariate normal).

$f(x)=\frac{1}{2 \pi|\Sigma|^{1 / 2}} e^{-\frac{1}{2}(x-\mu)^{\prime} \Sigma^{-1}(x-\mu)}$

The Sample Mean Vector and Covariance Matrix

Suppose that we have a random sample from a multivariate normal distribution-say, where the $i$ th sample vector contains observations on each of the $p$ variables $x i_{1}, x i_{2}, \ldots, x i_{p}$. Then the sample mean vector is

$$
\bar{x}_{j}=\frac{1}{n} \sum_{i=1}^{n} x_{i j}\{j=1,2, \ldots, p\}
$$

and the sample variance is

$$
s_{j}^{2}=\frac{1}{n-1} \sum_{i=1}^{n}\left(x_{i j}-\bar{x}_{j}\right)^{2} \quad\{j=1,2, \ldots, p\}
$$

and the sample covariance is

$$
s_{j h k}=\frac{1}{n-1} \sum_{i=1}^{n}\left(x_{i j k}-\bar{x}_{j k}\right)\left(x_{i h k}-\bar{x}_{h k}\right)\left\{\begin{array}{c}
k=1,2, \ldots, m \\
j \neq h
\end{array}\right.
$$

\subsection{HOTELLING T ${ }^{2}$ CONTROL CHART}

It is the most familiar multivariate process-monitoring and control procedure. Hotelling $T^{2}$ control chart is for monitoring the mean vector of the process. It is a direct analog of the univariate Shewhart chart. There are two versions of the Hotelling $T^{2}$ charts which are Subgrouped data and Individual observations.

\section{SUBGROUPED DATA}

Suppose that $p$ quality characteristics $x_{1}, x_{2}, \ldots, x_{\mathrm{p}}$ are jointly distributed according to the multivariate normal distribution (see equation 3.6.4). Let $\mu_{1}, \mu_{2}, \ldots, \mu_{\mathrm{p}}$ be the mean values of the quality characteristics and let $\sigma_{\mathrm{jk}}$ 's represent the variance-covariance values of the p-characteristics. In practice, it is usually necessary to estimate $\Sigma$ and $\mu$ from the preliminary samples of size $\mathrm{n}$, taken when the process is assumed to be in control. Suppose that $m$ such samples are available. the sample means and variances are calculated from each sample as usual; that is,

$$
\begin{aligned}
\bar{x}_{j k} & =\frac{1}{n} \sum_{i=1}^{n} x_{i j k}\left\{\begin{array}{l}
j=1,2, \ldots, p \\
k=1,2, \ldots, m
\end{array}\right. \\
s_{j k}^{2} & =\frac{1}{n-1} \sum_{i=1}^{n}\left(x_{i j k}-\bar{x}_{j k}\right)^{2}\left\{\begin{array}{l}
j=1,2, \ldots, p \\
k=1,2, \ldots, m
\end{array}\right.
\end{aligned}
$$

where $\boldsymbol{x}_{\boldsymbol{i} \boldsymbol{k} \boldsymbol{k}}$ is the $i$ th observation on the $j$ th quality characteristics in the $k$ th sample. The covariance between quality characteristic $j$ and quality characteristic $h$ in the $k$ th sample is

$$
s_{j h k}=\frac{1}{n-1} \sum_{i=1}^{n}\left(x_{i j k}-\bar{x}_{j k}\right)\left(x_{i h k}-\bar{x}_{h k}\right)\left\{\begin{array}{c}
k=1,2, \ldots, m \\
j \neq h
\end{array}\right.
$$

The statistics $\overline{\boldsymbol{x}}_{\boldsymbol{j} \boldsymbol{k}}, \boldsymbol{s}_{\boldsymbol{j} \boldsymbol{k}}^{2}$ and $\boldsymbol{s}_{\boldsymbol{j} \boldsymbol{k} \boldsymbol{k}}$ are then averaged over all $m$ samples to obtain 
and

$$
\overline{\bar{x}}_{j}=\frac{1}{m} \sum_{k=1}^{m} \bar{x}_{j} \ldots \ldots \ldots \ldots(3.6 .12) \quad \bar{s}_{j}^{2}=\frac{1}{m} \sum_{k=1}^{m} s_{j k}^{2}
$$

$$
\bar{s}_{j h}=\frac{1}{m} \sum_{k=1}^{m} s_{j h k}
$$

The $\left\{\overline{\overline{\boldsymbol{x}}}_{\boldsymbol{j}}\right\}$ are the elements of the vector $\overline{\overline{\boldsymbol{x}}}$, and the $p$ x $p$ average of sample covariance matrices $\mathrm{S}$ is formed as

$$
S=\left[\begin{array}{ccc}
\bar{s}_{1}^{2} & \cdots & \bar{s}_{1 p} \\
\vdots & \ddots & \vdots \\
\bar{s}_{p 1} & \cdots & \bar{s}_{p}^{2}
\end{array}\right]
$$

To use the $\mathrm{T}^{2}$ Control Chart, we will use the test statistics;

$$
T^{2}=n(\bar{x}-\overline{\bar{x}})^{\prime} S^{-1}(\bar{x}-\overline{\bar{x}})
$$

In this form, the procedure is usually called the Hotelling $\mathrm{T}^{2}$ control chart. This is a directionally invariant control chart; that is, its ability to detect a shift in the mean vector only depends on the magnitude of the shift, and not in its direction. There are two distinct phases of control chart usage.

PHASE I is the use of the charts for establishing control; that is, testing whether the process is in control when the $m$ preliminary subgroups are drawn. The control limit for $\mathrm{T}^{2}$ control chart are given by

$$
U C L=\frac{p(m-1)(n-1)}{m n-m-p+1} F_{\propto, p, m n-m-p+1} \quad \text { and } \quad L C L=0
$$

PHASE II is the use of the chart for monitoring future production, sample size of at least $n=200$ is needed. The control limits are as follows:

$$
U C L=\frac{p(m+1)(n-1)}{m n-m-p+1} F_{\propto, p, m n-m-p+1} \quad \text { and } \quad L C L=0
$$

\section{INDIVIDUAL OBSERVATION}

Here, multivariate control charts with subgroup size, $n=1$ is of interest. Suppose that $m$ samples, each of size $n=$ 1 , are available and that $p$ is the number of quality characteristics observed in each sample. Let $\bar{x}$ and S be the sample mean vector and covariance matrix, respectively, of these observations. The Hotelling $\mathrm{T}^{2}$ statistic in equation becomes

$$
T^{2}=(x-\bar{x})^{\prime} S^{-1}(x-\bar{x})
$$

The phase II control limits for this statistic are

$$
U C L=\frac{p(m+1)(m-1)}{m^{2}-m p} F_{\propto, p, m-p} \quad \text { and } \quad L C L=0
$$

When the number of preliminary samples $m$ is large, say $m>100$, most practitioners use an approximate control limit, either

$$
\begin{aligned}
U C L & =\frac{p(m-1)}{m-p} F_{\propto, p, m-p} \\
U C L & =X_{\propto, p}^{2}
\end{aligned}
$$

However, for $m>100$, equation (3.3.21) is a reasonable approximation.

For PHASE I, the limits are based on a beta distribution,

$$
U C L=\frac{(m-1)^{2}}{m} \beta_{\propto, p / 2,(m-p-1) / 2} \quad \text { and } \quad L C L=0
$$

Where $\boldsymbol{\beta}_{\propto, \boldsymbol{p} / \mathbf{2},(\boldsymbol{m}-\boldsymbol{p}-\mathbf{1}) / \mathbf{2}}$ is the upper $\alpha$ percentage point of a beta distribution with parameters $\mathrm{p} / 2$ and (m-p-1)/2. Approximations to the phase I limits based on the $\mathrm{F}$ and chi-square distributions are likely to be inaccurate. Basically, the focus will be on the Subgrouped data because it suits the type of data that was collected.

\subsection{CONTROL CHART FOR MONITORING VARIABILITY}

Monitoring multivariate process are in two levels, which are to monitor the process mean vector $m$ and to monitor process variability. Process variability is summarized by the $p \times p$ covariance matrix $\Sigma$. The main diagonal elements of this matrix are the variances of the individual process variables, and the off-diagonal elements are the covariances. We can use the approach based on the sample generalized variance, $|\mathrm{S}|$. This statistic, which is the determinant of the sample covariance matrix, is a widely used measure of multivariate dispersion. Another method would be to use the mean and variance of $|\mathrm{S}|$, that is, $E(|\mathrm{~S}|)$ and $V(|\mathrm{~S}|)$, and the property that most of the probability distribution of $|\mathrm{S}|$ is contained in the interval $\boldsymbol{E}(|\mathbf{S}|) \pm \mathbf{3} \sqrt{ }(\boldsymbol{V}(|\mathbf{S}|))$. It can be shown that

where

$$
E(|S|)=b_{1}|\Sigma| \quad \text { and } \quad V(|S|)=b_{2}|\Sigma|^{2}
$$




$$
b_{1}=\frac{1}{(n-1)^{p}} \prod_{i=1}^{p}(n-i)
$$

and

$$
b_{2}=\frac{1}{(n-1)^{2 p}} \prod_{i=1}^{p}(n-i)\left[\prod_{j=1}^{p}(n-j+2)-\prod_{j=1}^{p}(n-j)\right]
$$

Therefore, the parameters of the control charts for $|\mathrm{S}|$ would be

$$
\begin{aligned}
& U C L=|\Sigma|\left(b_{1}+3 b_{2}^{\frac{1}{2}}\right) \\
& C L=b_{1}|\Sigma| \\
& L C L=|\Sigma|\left(b_{1}+3 b_{2}^{1 / 2}\right)
\end{aligned}
$$

The lower control limit in equation (27) is replaced with zero if the calculated value is less than zero.

In practice, $\Sigma$ usually will be estimated by a sample covariance matrix $\mathrm{S}$, based on the analysis of preliminary samples. If this is the case, we should replace $|\Sigma|$ in equation (27) by $|\mathrm{S}| / b_{1}$

In this study, two measurement quality characteristics are being analyzed using Multivariate statistical quality control.

- Fill height: It measures the level of liquid in a bottle of drink. The products under study are STAR, MALTINA and GOLDBERG from Nigerian Breweries plc. The standard is always at $60 \mathrm{cl}$.

- $\mathrm{CO}_{2}$ level: It measures the level of $\mathrm{co}_{2}$ in each bottle. The target for corking a bottle of STAR is between $(0.52-0.54 \% \mathrm{wt} / \mathrm{wt})$, that of MALTINA is $(0.59-0.61 \% \mathrm{wt} / \mathrm{wt})$ and GOLDBERG is $(0.62-0.64 \% \mathrm{wt} / \mathrm{wt})$ where $\% \mathrm{wt} / \mathrm{wt}$ means weight per weight.

\subsection{DATA PRESENTATION}

NOTE: A, B, C, D, and E are the numbers of observations for each samples respectively.

TABLE 1: Showing the data of the fill height measurement of star in cl

\begin{tabular}{|l|l|l|l|l|l|l|}
\hline SAMPLE NO & TIME & A & B & C & D & E \\
\hline 1 & $7: 00 \mathrm{am}$ & 60 & 59 & 60 & 62 & 59 \\
\hline 2 & $8: 00 \mathrm{am}$ & 59 & 58 & 60 & 60 & 61 \\
\hline 3 & $9: 00 \mathrm{am}$ & 59 & 60 & 60 & 61 & 59 \\
\hline 4 & $10: 00 \mathrm{am}$ & 60 & 61 & 61 & 59 & 59 \\
\hline 5 & $11: 00 \mathrm{am}$ & 60 & 59 & 60 & 58 & 62 \\
\hline 6 & $12 \mathrm{noon}$ & 61 & 59 & 60 & 59 & 61 \\
\hline 7 & $1: 00 \mathrm{pm}$ & 60 & 59 & 59 & 58 & 61 \\
\hline 8 & $2: 00 \mathrm{pm}$ & 62 & 60 & 59 & 60 & 59 \\
\hline 9 & $3: 00 \mathrm{pm}$ & 58 & 62 & 60 & 59 & 61 \\
\hline 10 & $4: 00 \mathrm{pm}$ & 60 & 59 & 59 & 60 & 59 \\
\hline 11 & $5: 00 \mathrm{pm}$ & 61 & 59 & 61 & 60 & 59 \\
\hline 12 & $6: 00 \mathrm{pm}$ & 60 & 59 & 59 & 61 & 59 \\
\hline 13 & $7: 00 \mathrm{pm}$ & 58 & 60 & 60 & 61 & 61 \\
\hline 14 & $8: 00 \mathrm{pm}$ & 57 & 60 & 61 & 61 & 60 \\
\hline 15 & $9: 00 \mathrm{pm}$ & 59 & 61 & 59 & 60 & 61 \\
\hline 16 & $10: 00 \mathrm{pm}$ & 60 & 59 & 60 & 60 & 59 \\
\hline 17 & $11: 00 \mathrm{pm}$ & 58 & 60 & 62 & 59 & 61 \\
\hline 18 & $12: 00 \mathrm{am}$ & 59 & 60 & 59 & 62 & 59 \\
\hline 19 & $1: 00 \mathrm{am}$ & 59 & 60 & 59 & 60 & 61 \\
\hline 20 & $2: 00 \mathrm{am}$ & 60 & 60 & 59 & 59 & 62 \\
\hline & & & & & & \\
\hline
\end{tabular}


TABLE 2: Showing the data of the level of $\mathrm{CO}_{2}$ in each bottle of star in wt/wt

\begin{tabular}{|l|l|l|l|l|l|l|}
\hline SAMPLE NO & TIME & A & B & C & D & E \\
\hline 1 & $7: 00 \mathrm{am}$ & 0.52 & 0.51 & 0.50 & 0.55 & 0.51 \\
\hline 2 & $8: 00 \mathrm{am}$ & 0.55 & 0.50 & 0.54 & 0.53 & 0.53 \\
\hline 3 & $9: 00 \mathrm{am}$ & 0.53 & 0.52 & 0.52 & 0.52 & 0.51 \\
\hline 4 & $10: 00 \mathrm{am}$ & 0.54 & 0.54 & 0.52 & 0.52 & 0.53 \\
\hline 5 & $11: 00 \mathrm{am}$ & 0.53 & 0.56 & 0.55 & 0.54 & 0.55 \\
\hline 6 & $12 \mathrm{noon}$ & 0.51 & 0.52 & 0.54 & 0.53 & 0.53 \\
\hline 7 & $1: 00 \mathrm{pm}$ & 0.52 & 0.51 & 0.53 & 0.51 & 0.51 \\
\hline 8 & $2: 00 \mathrm{pm}$ & 0.53 & 0.52 & 0.52 & 0.53 & 0.51 \\
\hline 9 & $3: 00 \mathrm{pm}$ & 0.54 & 0.54 & 0.54 & 0.56 & 0.56 \\
\hline 10 & $4: 00 \mathrm{pm}$ & 0.52 & 0.54 & 0.53 & 0.51 & 0.54 \\
\hline 11 & $5: 00 \mathrm{pm}$ & 0.51 & 0.53 & 0.51 & 0.52 & 0.50 \\
\hline 12 & $6: 00 \mathrm{pm}$ & 0.53 & 0.54 & 0.54 & 0.53 & 0.53 \\
\hline 13 & $7: 00 \mathrm{pm}$ & 0.55 & 0.56 & 0.53 & 0.54 & 0.56 \\
\hline 14 & $8: 00 \mathrm{pm}$ & 0.56 & 0.55 & 0.53 & 0.50 & 0.54 \\
\hline 15 & $9: 00 \mathrm{pm}$ & 0.54 & 0.51 & 0.52 & 0.51 & 0.50 \\
\hline 16 & $10: 00 \mathrm{pm}$ & 0.55 & 0.56 & 0.55 & 0.54 & 0.55 \\
\hline 17 & $11: 00 \mathrm{pm}$ & 0.52 & 0.52 & 0.53 & 0.53 & 0.52 \\
\hline 18 & $12: 00 \mathrm{am}$ & 0.54 & 0.54 & 0.52 & 0.53 & 0.54 \\
\hline 19 & $1: 00 \mathrm{am}$ & 0.52 & 0.51 & 0.52 & 0.54 & 0.53 \\
\hline 20 & $2: 00 \mathrm{am}$ & 0.51 & 0.54 & 0.53 & 0.56 & 0.50 \\
\hline
\end{tabular}

TABLE 3: Showing the data of the fill height measurement of maltina in cl

\begin{tabular}{|l|l|l|l|l|l|l|}
\hline SAMPLE NO & TIME & A & B & C & D & E \\
\hline 1 & $7: 00 \mathrm{am}$ & 61 & 59 & 60 & 61 & 59 \\
\hline 2 & $8: 00 \mathrm{am}$ & 59 & 58 & 60 & 60 & 61 \\
\hline 3 & $9: 00 \mathrm{am}$ & 60 & 60 & 60 & 61 & 58 \\
\hline 4 & $10: 00 \mathrm{am}$ & 60 & 60 & 61 & 60 & 59 \\
\hline 5 & $11: 00 \mathrm{am}$ & 61 & 59 & 60 & 58 & 60 \\
\hline 6 & $12 \mathrm{noon}$ & 60 & 59 & 60 & 60 & 61 \\
\hline 7 & $1: 00 \mathrm{pm}$ & 59 & 60 & 58 & 61 & 59 \\
\hline 8 & $2: 00 \mathrm{pm}$ & 60 & 60 & 60 & 60 & 60 \\
\hline 9 & $3: 00 \mathrm{pm}$ & 58 & 61 & 62 & 58 & 61 \\
\hline 10 & $4: 00 \mathrm{pm}$ & 58 & 59 & 60 & 61 & 59 \\
\hline 11 & $5: 00 \mathrm{pm}$ & 61 & 60 & 61 & 58 & 60 \\
\hline 12 & $6: 00 \mathrm{pm}$ & 60 & 60 & 59 & 60 & 59 \\
\hline 13 & $7: 00 \mathrm{pm}$ & 59 & 61 & 59 & 61 & 60 \\
\hline 14 & $8: 00 \mathrm{pm}$ & 59 & 60 & 60 & 61 & 59 \\
\hline 15 & $9: 00 \mathrm{pm}$ & 59 & 62 & 60 & 59 & 60 \\
\hline 16 & $10: 00 \mathrm{pm}$ & 59 & 60 & 58 & 61 & 60 \\
\hline 17 & $11: 00 \mathrm{pm}$ & 60 & 59 & 61 & 60 & 60 \\
\hline 18 & $12: 00 \mathrm{am}$ & 60 & 61 & 59 & 60 & 59 \\
\hline 19 & $1: 00 \mathrm{am}$ & 62 & 59 & 60 & 59 & 59 \\
\hline 20 & $2: 00 \mathrm{am}$ & 59 & 60 & 60 & 59 & 62 \\
\hline
\end{tabular}


TABLE 4: Showing the data of the level of $\mathrm{CO}_{2}$ in each bottle of maltina in $\mathrm{wt} / \mathrm{wt}$

\begin{tabular}{|l|l|l|l|l|l|l|}
\hline SAMPLE NO & TIME & A & B & C & D & E \\
\hline 1 & $7: 00 \mathrm{am}$ & 0.60 & 0.60 & 0.59 & 0.60 & 0.59 \\
\hline 2 & $8: 00 \mathrm{am}$ & 0.58 & 0.58 & 0.59 & 0.60 & 0.60 \\
\hline 3 & $9: 00 \mathrm{am}$ & 0.59 & 0.60 & 0.60 & 0.61 & 0.59 \\
\hline 4 & $10: 00 \mathrm{am}$ & 0.59 & 0.61 & 0.61 & 0.60 & 0.58 \\
\hline 5 & $11: 00 \mathrm{am}$ & 0.60 & 0.60 & 0.60 & 0.60 & 0.59 \\
\hline 6 & $12 \mathrm{noon}$ & 0.59 & 0.59 & 0.59 & 0.60 & 0.60 \\
\hline 7 & $1: 00 \mathrm{pm}$ & 0.60 & 0.60 & 0.61 & 0.60 & 0.60 \\
\hline 8 & $2: 00 \mathrm{pm}$ & 0.60 & 0.61 & 0.60 & 0.59 & 0.59 \\
\hline 9 & $3: 00 \mathrm{pm}$ & 0.59 & 0.61 & 0.60 & 0.59 & 0.60 \\
\hline 10 & $4: 00 \mathrm{pm}$ & 0.60 & 0.60 & 0.60 & 0.60 & 0.61 \\
\hline 11 & $5: 00 \mathrm{pm}$ & 0.62 & 0.61 & 0.61 & 0.60 & 0.60 \\
\hline 12 & $6: 00 \mathrm{pm}$ & 0.61 & 0.61 & 0.61 & 0.60 & 0.61 \\
\hline 13 & $7: 00 \mathrm{pm}$ & 0.61 & 0.62 & 0.60 & 0.61 & 0.60 \\
\hline 14 & $8: 00 \mathrm{pm}$ & 0.62 & 0.60 & 0.60 & 0.61 & 0.62 \\
\hline 15 & $9: 00 \mathrm{pm}$ & 0.60 & 0.61 & 0.60 & 0.61 & 0.60 \\
\hline 16 & $10: 00 \mathrm{pm}$ & 0.61 & 0.59 & 0.60 & 0.61 & 0.60 \\
\hline 17 & $11: 00 \mathrm{pm}$ & 0.60 & 0.60 & 0.60 & 0.60 & 0.61 \\
\hline 18 & $12: 00 \mathrm{am}$ & 0.60 & 0.61 & 0.59 & 0.59 & 0.59 \\
\hline 19 & $1: 00 \mathrm{am}$ & 0.59 & 0.60 & 0.58 & 0.60 & 0.61 \\
\hline 20 & $2: 00 \mathrm{am}$ & 0.58 & 0.60 & 0.59 & 0.60 & 0.59 \\
\hline
\end{tabular}

TABLE 5: Showing the data of the fill height measurement of Goldberg in cl

\begin{tabular}{|l|l|l|l|l|l|l|}
\hline SAMPLE NO & TIME & A & B & C & D & E \\
\hline 1 & $7: 00 \mathrm{am}$ & 61 & 60 & 59 & 61 & 59 \\
\hline 2 & $8: 00 \mathrm{am}$ & 59 & 58 & 60 & 60 & 61 \\
\hline 3 & $9: 00 \mathrm{am}$ & 59 & 60 & 59 & 61 & 60 \\
\hline 4 & $10: 00 \mathrm{am}$ & 61 & 60 & 60 & 59 & 60 \\
\hline 5 & $11: 00 \mathrm{am}$ & 59 & 60 & 60 & 59 & 60 \\
\hline 6 & $12 \mathrm{noon}$ & 61 & 59 & 60 & 59 & 61 \\
\hline 7 & $1: 00 \mathrm{pm}$ & 59 & 60 & 60 & 58 & 60 \\
\hline 8 & $2: 00 \mathrm{pm}$ & 60 & 61 & 59 & 60 & 60 \\
\hline 9 & $3: 00 \mathrm{pm}$ & 58 & 61 & 62 & 58 & 61 \\
\hline 10 & $4: 00 \mathrm{pm}$ & 58 & 59 & 60 & 61 & 59 \\
\hline 11 & $5: 00 \mathrm{pm}$ & 61 & 60 & 61 & 58 & 60 \\
\hline 12 & $6: 00 \mathrm{pm}$ & 60 & 60 & 59 & 60 & 59 \\
\hline 13 & $7: 00 \mathrm{pm}$ & 60 & 59 & 60 & 61 & 60 \\
\hline 14 & $8: 00 \mathrm{pm}$ & 57 & 60 & 61 & 61 & 60 \\
\hline 15 & $9: 00 \mathrm{pm}$ & 59 & 61 & 59 & 60 & 61 \\
\hline 16 & $10: 00 \mathrm{pm}$ & 59 & 60 & 58 & 61 & 60 \\
\hline 17 & $11: 00 \mathrm{pm}$ & 60 & 59 & 61 & 60 & 60 \\
\hline 18 & $12: 00 \mathrm{am}$ & 60 & 61 & 59 & 60 & 59 \\
\hline 19 & $1: 00 \mathrm{am}$ & 59 & 60 & 59 & 60 & 60 \\
\hline 20 & $2: 00 \mathrm{am}$ & 60 & 59 & 60 & 61 \\
\hline
\end{tabular}


TABLE 6: Showing the data of the level of $\mathrm{CO}_{2}$ in each bottle of Goldberg in $w t / w t$

\begin{tabular}{|l|l|l|l|l|l|l|}
\hline SAMPLE NO & TIME & A & B & C & D & E \\
\hline 1 & $7: 00 \mathrm{am}$ & 0.65 & 0.64 & 0.64 & 0.65 & 0.63 \\
\hline 2 & $8: 00 \mathrm{am}$ & 0.63 & 0.63 & 0.64 & 0.65 & 0.63 \\
\hline 3 & $9: 00 \mathrm{am}$ & 0.61 & 0.63 & 0.65 & 0.62 & 0.64 \\
\hline 4 & $10: 00 \mathrm{am}$ & 0.64 & 0.64 & 0.64 & 0.63 & 0.62 \\
\hline 5 & $11: 00 \mathrm{am}$ & 0.63 & 0.62 & 0.61 & 0.64 & 0.63 \\
\hline 6 & $12 \mathrm{noon}$ & 0.62 & 0.64 & 0.64 & 0.63 & 0.62 \\
\hline 7 & $1: 00 \mathrm{pm}$ & 0.63 & 0.65 & 0.64 & 0.63 & 0.64 \\
\hline 8 & $2: 00 \mathrm{pm}$ & 0.64 & 0.66 & 0.62 & 0.63 & 0.61 \\
\hline 9 & $3: 00 \mathrm{pm}$ & 0.65 & 0.66 & 0.64 & 0.64 & 0.64 \\
\hline 10 & $4: 00 \mathrm{pm}$ & 0.64 & 0.64 & 0.63 & 0.63 & 0.63 \\
\hline 11 & $5: 00 \mathrm{pm}$ & 0.64 & 0.63 & 0.65 & 0.65 & 0.65 \\
\hline 12 & $6: 00 \mathrm{pm}$ & 0.62 & 0.64 & 0.63 & 0.64 & 0.63 \\
\hline 13 & $7: 00 \mathrm{pm}$ & 0.63 & 0.63 & 0.63 & 0.63 & 0.64 \\
\hline 14 & $8: 00 \mathrm{pm}$ & 0.64 & 0.66 & 0.64 & 0.64 & 0.65 \\
\hline 15 & $9: 00 \mathrm{pm}$ & 0.64 & 0.66 & 0.64 & 0.65 & 0.64 \\
\hline 16 & $10: 00 \mathrm{pm}$ & 0.63 & 0.62 & 0.62 & 0.63 & 0.64 \\
\hline 17 & $11: 00 \mathrm{pm}$ & 0.64 & 0.64 & 0.64 & 0.62 & 0.63 \\
\hline 18 & $12: 00 \mathrm{am}$ & 0.62 & 0.64 & 0.64 & 0.62 & 0.63 \\
\hline 19 & $1: 00 \mathrm{am}$ & 0.62 & 0.64 & 0.65 & 0.62 & 0.64 \\
\hline 20 & $2: 00 \mathrm{am}$ & 0.62 & 0.63 & 0.63 & 0.63 & 0.64 \\
\hline
\end{tabular}

\section{DATA ANALYSIS}

In this chapter, the Hotelling $T^{2}$ control chart is used for the analysis of fill height and level of $\mathrm{co}_{2}$ measurements of STAR, MALTINA and GOLDBERG using R.

ANALYSIS ON THE FILL HEIGHT MEASUREMENT AND CO2 LEVEL OF STAR

The fill height of STAR refers to the height of the liquid content in a bottle of a STAR. And the Co2 level refers to the level of co2 in each bottle of STAR. There can be cases of low fill, high fill and normal fill. The normal or standard fill height of STAR of the company is $60 \mathrm{cl}$. And the standard co2 level of STAR is between $(0.52-$ $0.54 \% \mathrm{wt} / \mathrm{wt}$ ). The tables below display analysis carried out using $\mathrm{R}$ on various readings on fill height and co 2 level that was observed at different times.

Table 7.0 STAR

\begin{tabular}{|c|c|c|c|c|c|c|c|}
\hline & \multicolumn{2}{|l|}{ Means } & \multicolumn{3}{|c|}{ Variance and Covariances } & \multicolumn{2}{|c|}{ Control Chart Statistics } \\
\hline $\begin{array}{l}\text { Sample } \\
\text { Number k }\end{array}$ & $\begin{array}{ll}\text { Fill } & \text { Height } \\
\left(\overline{\boldsymbol{x}}_{1 \mathrm{k}}\right) & \end{array}$ & $\begin{array}{lll}\text { Level of } & \mathrm{CO}_{2} \\
\left(\overline{\boldsymbol{x}}_{2 \mathrm{k}}\right) & & \end{array}$ & $\mathrm{S}^{2}{ }_{1 \mathrm{k}}$ & $\mathrm{S}^{2}{ }_{2 \mathrm{k}}$ & $\mathrm{S}_{12 \mathrm{k}}$ & $\begin{array}{l}\text { Hotelling } \\
\mathrm{T}^{2}{ }_{\mathrm{k}}\end{array}$ & $\left|\mathrm{S}_{\mathrm{k}}\right|$ \\
\hline 1 & 60.0 & 0.518 & 1.5 & 0.00037 & 0.0200 & 3.8339370 & 0.00015500 \\
\hline 2 & 59.6 & 0.530 & 1.3 & 0.00035 & 0.0100 & 0.1962245 & 0.00035500 \\
\hline 3 & 59.8 & 0.520 & 0.7 & 0.00005 & 0.0000 & 2.6772350 & 0.00003500 \\
\hline 4 & 60.0 & 0.530 & 1.0 & 0.00010 & 0.0025 & 0.1181133 & 0.00009375 \\
\hline 5 & 59.8 & 0.546 & 2.2 & 0.00013 & 0.0015 & 7.7073474 & 0.00028375 \\
\hline 6 & 60.0 & 0.526 & 1.0 & 0.00013 & -0.0025 & 0.4357597 & 0.00012375 \\
\hline 7 & 59.4 & 0.516 & 1.3 & 0.00008 & -0.0005 & 6.4532623 & 0.00010375 \\
\hline 8 & 60.0 & 0.522 & 1.5 & 0.00007 & 0.0075 & 1.6743676 & 0.00004875 \\
\hline 9 & 60.0 & 0.548 & 2.5 & 0.00012 & 0.0000 & 10.0856025 & 0.00030000 \\
\hline 10 & 59.4 & 0.528 & 0.3 & 0.00017 & -0.0065 & 0.8187689 & 0.00000875 \\
\hline 11 & 60.0 & 0.514 & 1.0 & 0.00013 & -0.0025 & 6.9144678 & 0.00012375 \\
\hline 12 & 59.6 & 0.534 & 0.8 & 0.00003 & -0.0030 & 0.6801556 & 0.00001500 \\
\hline 13 & 60.0 & 0.548 & 1.5 & 0.00017 & 0.0000 & 10.0856025 & 0.00025500 \\
\hline 14 & 59.8 & 0.536 & 2.7 & 0.00053 & -0.0285 & 1.1678815 & 0.00061875 \\
\hline 15 & 60.0 & 0.516 & 1.0 & 0.00023 & -0.0125 & 5.2590822 & 0.00007375 \\
\hline 16 & 59.6 & 0.550 & 0.3 & 0.00005 & -0.0025 & 11.8254949 & 0.00000875 \\
\hline 17 & 60.0 & 0.524 & 2.5 & 0.00003 & 0.0025 & 0.9399435 & 0.00006875 \\
\hline 18 & 59.8 & 0.534 & 1.7 & 0.00008 & -0.0015 & 0.5507094 & 0.00013375 \\
\hline 19 & 59.8 & 0.524 & 0.7 & 0.00013 & 0.0035 & 0.9184544 & 0.00007875 \\
\hline 20 & 60.0 & 0.528 & 1.5 & 0.00057 & -0.0225 & 0.1618163 & 0.00034875 \\
\hline Averages & 59.83 & 0.5296 & 1.5 & 0.00057 & -0.0225 & & \\
\hline
\end{tabular}


Table7.0 shows the Variances and Covariances of the fill height and level of $\mathrm{CO}_{2}$ of STAR and also the Hotelling $\mathrm{T}^{2}$ and Variability of each of the 20 samples. The Grand mean, Variance-Covariance Matrix (s) for the control limit used in the Variability plot, and the control Limits for the Hotelling $\mathrm{T}^{2}$ and Variability plot are represented in the table(s) below.

\begin{tabular}{|l|l|}
\multicolumn{2}{|c|}{ Grand Mean } \\
\hline Fill Height & 59.8300 \\
\hline Level of $\mathrm{CO}_{2}$ & 0.5296 \\
\hline
\end{tabular}

Variance-Covariance Matrix (S) for the control limit used in the variability plot

\begin{tabular}{|l|l|l|}
\hline & Fill Height & Level of $\mathrm{CO}_{2}$ \\
\hline Fill Height & 1.5000 & -0.02250 \\
\hline Level of $\mathrm{CO}_{2}$ & -0.0225 & 0.00057 \\
\hline
\end{tabular}

Control Limits for the Hotelling $T^{2}$ and Variability plot

\begin{tabular}{|l|l|l|l|}
\hline & LCL & CL & UCL \\
\hline Hotelling T & 0 & - & 14.523838130 \\
\hline Variability & 0 & 0.0002345375 & 0.001096283 \\
\hline
\end{tabular}

\section{INTERPRETATION OF STAR CHART}

From the Variability plot above, most of the sample variances are on or close to the lower control limit (LCL) while they are very far from the upper control limit, which means that the variability (the variances of the observation from the mean) is in control. Thus, the Hotelling $\mathrm{T}^{2}$ can be plotted to see if the process is actually in control. From the Hotelling $\mathrm{T}^{2}$ plotted above also, it can be seen that all the plot point fall within the UCL and LCL, which means that it can be concluded that the fill height and level of $\mathrm{Co}_{2}$ of STAR is under control. The $\mathrm{R}$ code was used for the analysis of STAR .

\section{ANALYSIS ON THE FILL HEIGHT MEASUREMENT AND CO2 LEVEL OF MALTINA}

The fill height of MALTINA refers to the height of the liquid content in a bottle of a MALTINA. And the Co2 level refers to the level of co2 in each bottle of MALTINA. There can be cases of low fill, high fill and normal fill. The normal or standard fill height of MALTINA of the company is $60 \mathrm{cl}$. And the standard co 2 level of MALTINA is between $(0.59-0.61 \% \mathrm{wt} / \mathrm{wt})$. The tables below display analysis carried out using $\mathrm{R}$ on various readings on fill height and co2 level that was observed at different times.

Table 8.0

\begin{tabular}{llll}
\multicolumn{3}{l}{ Means } & \\
Sample & Fill Height & $\begin{array}{l}\text { Level of } \mathrm{CO}_{2} \\
\left(\overline{\boldsymbol{x}}_{2 \mathrm{k}}\right)\end{array}$ \\
Number k & 60.0 & 0.596 \\
1 & 59.6 & 0.590 \\
2 & 59.8 & 0.598 \\
3 & 60.0 & 0.598 \\
4 & 59.6 & 0.598 \\
5 & 60.0 & 0.594 \\
6 & 59.4 & 0.602 \\
7 & 60.0 & 0.598 \\
8 & 60.0 & 0.598 \\
9 & 59.4 & 0.602 \\
10 & 60.0 & 0.608 \\
11 & 59.6 & 0.608 \\
12 & 60.0 & 0.608 \\
13 & 59.8 & 0.610 \\
14 & 60.0 & 0.604 \\
15 & 59.6 & 0.602 \\
16 & 60.0 & 0.602 \\
17 & 59.8 & 0.596 \\
18 & 59.8 & 0.596 \\
19 & 60.0 & 0.592 \\
20 & &
\end{tabular}

Variances

Covariances

$\mathrm{S}^{2}{ }_{1 \mathrm{k}} \quad \mathrm{S}^{2}{ }_{2 \mathrm{k}}$

$\begin{array}{ll}1.0 & 0.00003\end{array}$

$1.3 \quad 0.00010$

$1.2 \quad 0.00007$

$0.5 \quad 0.00017$

$\begin{array}{ll}1.3 & 0.00002\end{array}$

$0.5 \quad 0.00003$

$1.3 \quad 0.00002$

$\begin{array}{ll}0.0 & 0.00007\end{array}$

$3.5 \quad 0.00007$

$1.3 \quad 0.00002$

$\begin{array}{ll}1.5 & 0.00007\end{array}$

$0.3 \quad 0.00002$

$\begin{array}{ll}1.0 & 0.00007\end{array}$

$0.7 \quad 0.00010$

$\begin{array}{ll}1.5 & 0.00003\end{array}$

$\begin{array}{ll}1.3 & 0.00007\end{array}$

$0.5 \quad 0.00002$

$0.7 \quad 0.00008$

$\begin{array}{ll}1.7 & 0.00013\end{array}$

$\begin{array}{ll}1.5 & 0.00007\end{array}$ and Control Chart Statistics

$\begin{array}{lll}\mathrm{S}_{12 \mathrm{k}} & \begin{array}{l}\text { Hotelling } \\ \mathrm{T}^{2} \mathrm{k}\end{array} & \left|\mathrm{S}_{\mathrm{k}}\right| \\ 0.0025 & 1.7606748 & 0.00002375 \\ 0.0100 & 8.0208486 & 0.00003000 \\ 0.0070 & 0.3296529 & 0.00003500 \\ 0.0075 & 0.6161894 & 0.00002875 \\ -0.0010 & 0.4235547 & 0.00002500 \\ 0.0025 & 3.5875338 & 0.00000875 \\ -0.0035 & 1.4622119 & 0.00001375 \\ 0.0000 & 0.6161894 & 0.00000000 \\ 0.0125 & 0.6161894 & 0.00008875 \\ -0.0010 & 1.4622119 & 0.00002500 \\ 0.0075 & 5.1293660 & 0.00004875 \\ -0.0010 & 6.2803431 & 0.00000500 \\ 0.0050 & 5.1293660 & 0.00004500 \\ -0.0050 & 8.5987526 & 0.00004500 \\ 0.0025 & 1.2769746 & 0.00003875 \\ 0.0010 & 0.7191493 & 0.00009000 \\ 0.0000 & 0.3743393 & 0.00001000 \\ 0.0065 & 1.3397771 & 0.00001375 \\ -0.0085 & 1.3397771 & 0.00014875 \\ 0.0000 & 6.0967665 & 0.00010500\end{array}$


Table 8.0 shows the Variances and Covariances of the fill height and level of $\mathrm{Co}_{2}$ of MALTINA and also the Hotelling $\mathrm{T}^{2}$ and Variability of each of the 20 samples. The Grand mean, Variance-Covariance Matrix (s) for the control limit used in the Variability plot, and the control Limits for the Hotelling $\mathrm{T}^{2}$ and Variability plot are represented in the table(s) below.

Grand Mean

\begin{tabular}{l|l}
\hline Fill Height & 59.82 \\
\hline Level of $\mathrm{CO}_{2}$ & 0.60
\end{tabular}

Variance-Covariance Matrix (S) for the control limit used in the variability plot

\begin{tabular}{|l|l|l|}
\hline Fill Height & Fill Height & Level of $\mathrm{CO}_{2}$ \\
\hline Level of $\mathrm{CO}_{2}$ & 1.130000 & 0.002225 \\
\hline
\end{tabular}

Control Limits for the Hotelling $T^{2}$ and Variability plot

\begin{tabular}{|l|l|l|l|}
\hline & LCL & CL & UCL \\
\hline Hotelling T & 0 & - & 14.52384 \\
\hline Variability & 0 & 0.00006624 & 0.001096 \\
\hline
\end{tabular}

\section{Hotelling T_SQUARED PLOT}

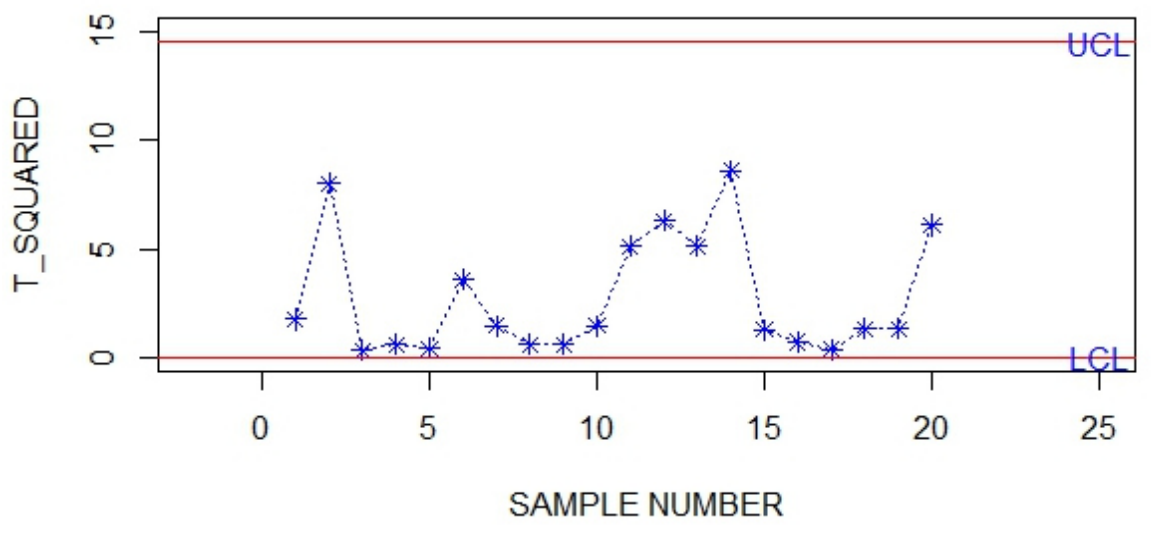

\section{INTERPRETATION OF MALTINA CHART}

From the Variability plot above, most of the sample variances are on or close to the lower control limit (LCL) while they are very far from the upper control limit, which means that the variability (the variances of the observation from the mean) is in control. Thus, the Hotelling $\mathrm{T}^{2}$ can be plotted to see if the process is actually in control. From the Hotelling $\mathrm{T}^{2}$ plotted above also, it can be seen that all the plot point fall within the UCL and LCL, which means that it can be concluded that the fill height and level of $\mathrm{Co}_{2}$ of MALTINA is under control.

\section{ANAL YSIS ON THE FILL HEIGHT MEASUREMENT AND CO2 LEVEL OF GOLDBERG}

The fill height of GOLDBERG refers to the height of the liquid content in a bottle of a GOLDBERG. And the Co2 level refers to the level of $\mathrm{CO}_{2}$ in each bottle of GOLDBERG. There can be cases of low fill, high fill and normal fill. The normal or standard fill height of GOLDBERG of the company is 60cl. And the standard level of $\mathrm{CO}_{2}$ GOLDBERG is between $(0.62-0.64 \% \mathrm{wt} / \mathrm{wt})$. The tables below display analysis carried out using $\mathrm{R}$ on various readings on fill height and $\mathrm{CO}_{2}$ level that was observed at different times. 


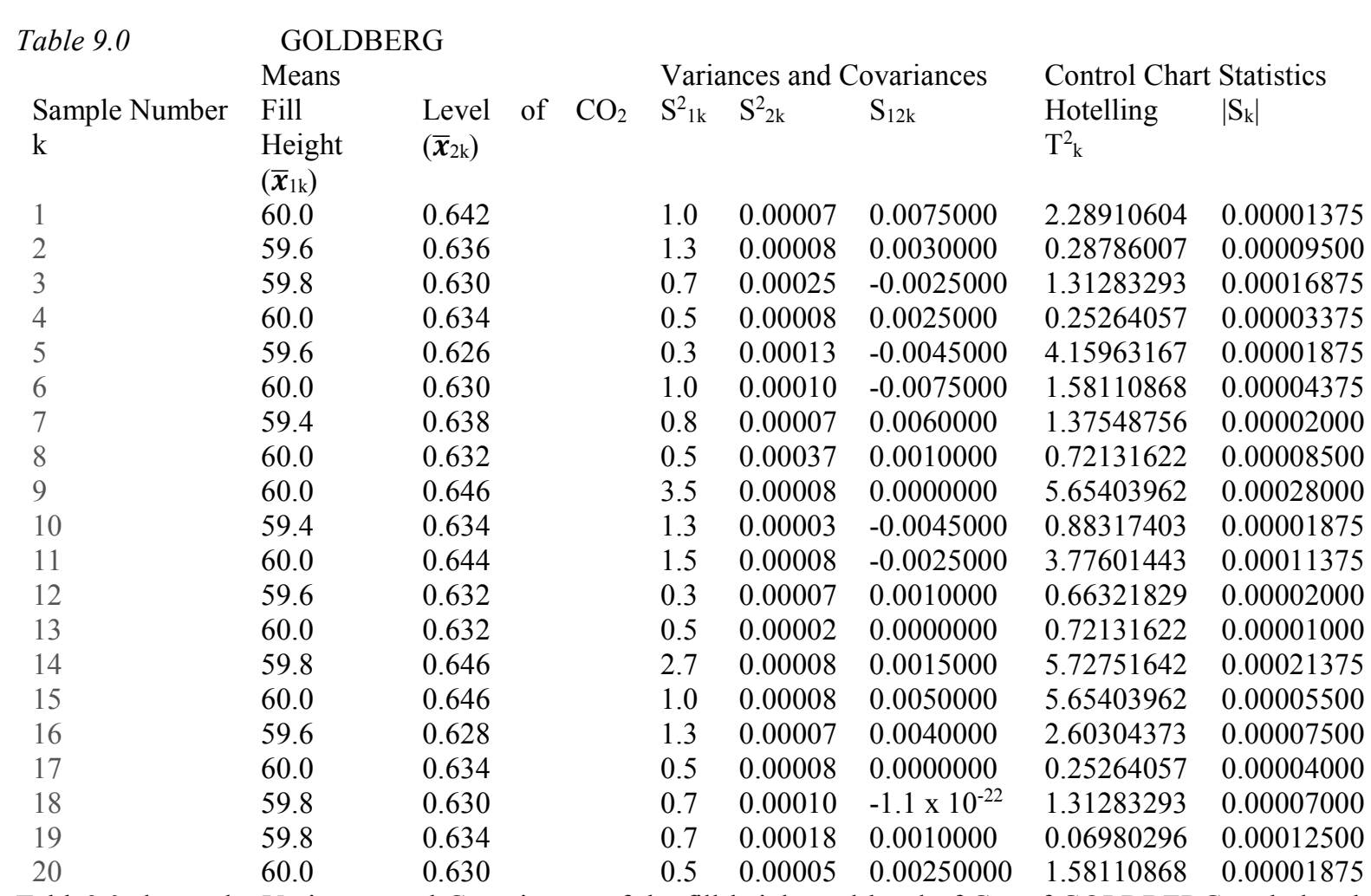

Table9.0 shows the Variances and Covariances of the fill height and level of $\mathrm{Co}_{2}$ of GOLDBERG and also the Hotelling $\mathrm{T}^{2}$ and Variability of each of the 20 samples. The Grand mean, Variance-Covariance Matrix (s) for the control limit used in the Variability plot, and the control Limits for the Hotelling $\mathrm{T}^{2}$ and Variability plot are represented in the table(s) below.

Grand Mean

\begin{tabular}{|l|l|}
\hline Fill Height & 59.820 \\
\hline Level of $\mathrm{CO}_{2}$ & 0.6352 \\
\hline
\end{tabular}

Variance-Covariance Matrix (S) for the control limit used in the variability plot

\begin{tabular}{|l|l|l|}
\hline Fill Height & Fill Height & Level of $\mathrm{CO}_{2}$ \\
\hline Level of $\mathrm{CO}_{2}$ & 1.0300000 & 0.0011250 \\
\hline
\end{tabular}

Control Limits for the Hotelling $\mathrm{T}^{2}$ and Variability plot

\begin{tabular}{|l|l|l|l|}
\hline & LCL & CL & UCL \\
\hline Hotelling T & 0 & - & 14.52384 \\
\hline Variability & 0 & 0.0001053 & 0.000492 \\
\hline
\end{tabular}



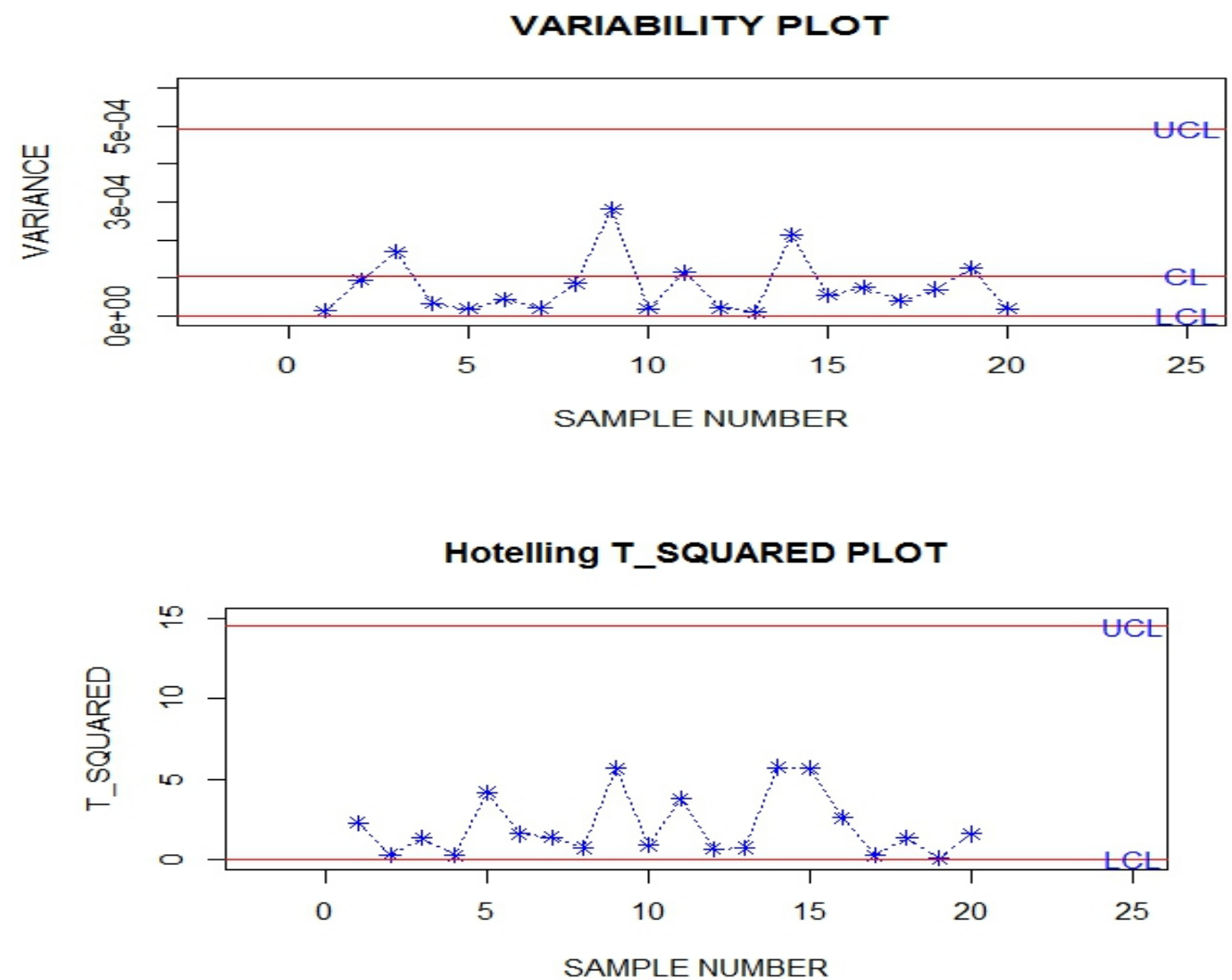

\section{INTERPRETATION OF GOLDBERG CHART}

From the Variability plot above, most of the sample variances are on or close to the lower control limit (LCL) while they are very far from the upper control limit, which means that the variability (the variances of the observation from the mean) is in control. Thus, the Hotelling $\mathrm{T}^{2}$ can be plotted to see if the process is actually in control. From the Hotelling $\mathrm{T}^{2}$ plotted above also, it can be seen that all the plot point fall within the UCL and $\mathrm{LCL}$, which means that it can be concluded that the fill height and level of $\mathrm{Co}_{2}$ of GOLDBERG is under control.

\section{RESULTS AND DISCUSSION}

Null Hypothesis[$\left[\mathrm{H}_{01}\right]$ : The fill height are in the proper proportions of production

Alternative Hypothesis $\left[\mathrm{H}_{\mathrm{A} 1}\right]$ : Not $\mathrm{H}_{01}$

Null Hypothesis[ $\left.\mathrm{H}_{\mathrm{O} 2}\right]$ : The level of $\mathrm{Co}_{2}$ are in the proper proportions of production

Alternative Hypothesis $\left[\mathrm{H}_{\mathrm{A} 2}\right]$ : Not $\mathrm{H}_{02}$

Based on the results obtained from the analysis so far for all the beer drinks considered, none of the characteristics examined and analyzed fall within the control which invariably means we do not have sufficient evidence to reject the null hypothesis hence we Accept the null hypothesis for both the fill height and the level of $\mathrm{Co}_{2}$.

\section{CONCLUSION}

The results obtained from the method used show that the components for the production of the beer under consideration (fill height and level of $\mathrm{Co}_{2}$ ) shows that the variability of the three products are in control, and this information helped in proceeding to check if the two quality characteristics are in control, also, using the Hotelling $\mathrm{T}^{2}$ control chart of Subgrouped data, the values were all within the lower and upper control limit for the three products, which helps to affirm the fact that the quality characteristics of STAR, MALTINA AND GOLDBERG are in control. This shows that the Quality Control Unit of the Company should not relent in carrying out quality test on the product. Due to the fact that there are many competing Brewery industries, there is need for indigenous company to always be of high quality so as to survive competition with other products from other companies

\section{REFERENCES}

Acebrón, L. B. \& Dopico, D. C. (2000). The importance of intrinsic and extrinsic cues to expected and experienced quality: An empirical application for beef. Food Quality and Preference, 11, 229-238. 
Ajzen, I. \& Fishbein, M. (1980). Understanding attitudes and predicting social behavior, 1st ed. Englewood Cliffs, NJ: Prentice-Hall.

Andersen, E. S. (1994). The evolution of credence goods: A transaction approach to product specification and quality control. MAPP working paper no 21 .

Askegaard, S. \& Brunsø, K. (1999). Food-related life styles in Singapore: Preliminary testing of a Western European research instrument in Southeast Asia. Journal of Euromarketing, 7, 65-86.

Baadsgaard, A., Grunert, K. G., Grunert, S. C. \& Skytte, H. (1994). Undersøgelse af mulighederne for eksport af økologiske mælkeprodukter til Nordtyskland. MAPP project paper.

Bech-Larsen, T. \& Grunert, K. G. (1998). Integrating the theory of planned behaviour with means-end chain theory - A study of possible improvements in predictive ability. 27th EMAC Conference, Stockholm, May.

Chaser RB and Aquilano N J 1989. Production and Operations Management A life cycle approach 5th Edn. Irwin Series in Quantitative Analysis for Business, p. 164.

Carter RJ and Price PM 1995. Integrated Materials Management; Therm. and E. 2ndEdn. Handbook Series, p. 78 - 84. Dervirsiotis KN. Operations Management; International Student Edn. McGraw-Hill Inc., p. 648.

James C. Benneyan \& David Birn 1998. Methods in Infection Control and Hospital Epidemiology. Hospital Epidemiology, 19(3): 194-214.

Karim Houchi et al 2015. Statistical Quality Control of High Resolution Winds of Different Radiosode Types for Chmatology Analysis. Journal of Atmospheric and Oceanic Technology, 2015, 32 (10)

King-Scott Peter 1971. Production Control for Supervisors; 1st Edn. Collins, London and Glasgow, p. 95.

Mahosh BP and Prabhuswany MS 2010. Process Variability Reduction Through Statistica Process Control for Quality Improvement. Int. J. Quality Rese., 4(3): 193-203

Maria Emilia Camergo, Walter Paesnitz Filho, Angela Isabel dos Santos Bulius, Jose Maurcio Carre Maciel 2008. Statistical quality control. A case study research. Mgt. Innovation and Technology, 2008, ICMIT 2008, 4th IEEE International Conference Mayer Raymond R1975. Production and Operations Management; 3rd Edn. McGraw-Hill book Company Inc., p. 347. Mittag HJ and Rinne H1993.

Mason, B. and Jiju, A.J. (2007).“ Statistical process control.”An essential ingredient for improving service and manufacturing quality. Pp. 233-238

Shenawy, E. and Baker, T. (2007). "Analysis of the Effect of TQM on competitive Advantage." International Journal of Quality and Reliability management. Pp. 442-471.

Eze, J.I.et al (2005). "Statistics and quantitative methods for construction and business managers". The Nigerian institute of Building.

Ohta, H., Kimura, A. and Rahim,M.A. (2002). "An economic model for X and R chart with time-varying parameters," Quality and Reliability Engineering-International.Vol.18, no2, pp. 131-139.

Rahim,M.A. and Costa, A.F.B. (2000) "Joint economic design of X and R charts under Weibull shock model" International Journal of Production . Research Vol.28, no 13, pp.2871-2889. 